\title{
Analysis of External Environment's Moderating Role on the Entrepreneurial Orientation and Business Performance Relationship among Italian Small Enterprises
}

\author{
Bojan Moric Milovanovic and Zoran Wittine
}

\begin{abstract}
Scientific research of entrepreneurship has produced the concept of entrepreneurial orientation, which has grown into one of the most important factors when it comes to management research. Thus, the goal of this paper is to explore relations between the constructs of entrepreneurial orientation and business performance in small companies, as well as the moderating effects of external environment factors. Relation between the entrepreneurial orientation and performance is extremely complex because it is moderated by many internal and external factors. Although a lot of research on the topic has already been done, global changes condition the necessity for new findings in light of these changes. In order to gain new insights, authors conduct primary research.
\end{abstract}

Index Terms-Business performance, entrepreneurial orientation, external environment, Italy, SME.

\section{INTRODUCTION}

From the very emergence of the concept up until today, entrepreneurial orientation has received a lot of attention. Not only has the entrepreneurial orientation allowed us to better understand drivers behind the strategy and development path of particular organization [1], but has also enabled us to comprehend relations between the variable in place and different organizational and environmental factors. Although a lot of research on the topic has already been done, global technological, economic and social changes condition the necessity for new findings in light of these changes. Complexity and interdependence of factors constituting modern business environment affect emergence of new variable(s) creation that alter the existing relations.

On the other hand, various research show that small and medium-sized enterprises (SMEs) are among the main drivers of economic growth, but also one of the biggest sources of innovation and competitiveness, and the instigator of the international exchange. In the European Union the number of small and medium enterprises is estimated at over 17 million, and their direct and indirect effects on economic development are immeasurable. Notwithstanding the above, most of the scientific papers dealing with the concept of entrepreneurial orientation conducted their research focusing

Manuscript received January 7, 2014; revised March 24, 2014

Bojan Moric Milovanovic is with the Graduate School of Economics and Business, University of Zagreb, 10000 Zagreb, Croatia (e-mail: bmoric@efzg.hr).

Zoran Wittine is with the Faculty of Economics and Business, University of Zagreb, 10000 Zagreb, Croatia (e-mail: zoran.wittine@gmail.com). its efforts mostly on the experiences of large international companies.

All companies encounter similar problems in the marketplace regardless of the size of the business entity. However, SMEs will inevitably control fewer resources and be part of smaller information networks. Likewise, competencies within these companies will be less specialized. In addition, operating and control mechanisms of operations will be significantly different in SMEs than in large enterprises. Bonaccorsi [2] points out that the differences in the size of the company will not only be reflected in the quantity of disposable resources. These differences will be reflected in many other ways due to a number of characteristics immanent to the SMEs when compared to large companies. Along the same lines Welsh and White [3] point out that small business is not "minified large company." Therefore, we can not a priori assume that the business processes and mechanisms equally work and have a same effect in small and medium-sized and large enterprises. This in hand encouraged us to conduct a research which could explain in more details nature of relations of entrepreneurial orientation within SMEs.

\section{LITERATURE REVIEW AND HYPOTHESES}

Although there is no generally accepted definition, we can say that entrepreneurship is a concept that encompasses a way of thinking and acting within the company. Most definitions of entrepreneurship imply active seeking and exploration of market opportunities in order to achieve above the average results. According to Knight [4], entrepreneurship implies struggling with the market and technological uncertainties and willingness to take risks in this regard. According to Schumpeter [5], entrepreneurship involves the introduction of new products, processes, organization, distribution channel, etc. depending on market requirements. Furthermore, entrepreneurship involves "intentional creation or transformation of the organization with the aim of creating or adding value through the organization of resources" [6].

Scientific research of entrepreneurship has produced the concept of entrepreneurial orientation, which has grown into one of the most important factors when it comes to management research and its attempts to explain the differences in performance of companies [7]. It is a multi-dimensional variable, and is determined by five structural components: proactiveness, innovativeness, risk taking, autonomy and competitive aggressiveness [8].

Proactiveness refers to the process of new opportunities 
discovery (which may or may not be associated with the current business activities of the company), placing new products into market before the competition and strategic elimination of products that are in declining stages of product life cycle [9], as well as forecasting competitors' moves and market needs [10]. According to Wiklund and Shepherd [11] proactiveness promotes identification of new market opportunities and allows for quick action to capitalize on in order to achieve high profits, while Lumpkin and Dess [12] explain it involves active monitoring of changes in the market environment, consumer tastes and applied technologies.

Innovativeness refers to the company's efforts aimed at discovering new products and/or services, and the enhancement of existing systems and processes or the tendency of companies to develop and support new ideas, experimentation and creative processes that may result in new products, services or technological processes [8]. Innovativeness leads to business success achievement by taking advantage of new opportunities that arise from changes in the business environment [13].

Risk taking reflects willingness to use resources in projects in which the probability of failure is high and the results are unknown [11], respectively a willingness to move into the unknown without knowledge of the possible outcomes [14]. Investing in unfamiliar technology, entering unconventional markets, leveraging business operations are all examples of risk taking behavior [15].

Autonomy refers to the independence required for the identification of opportunities and their exploitation through the implementation of business concepts [16]. In other words, autonomy implies discretion and independent action of individuals at all levels of the company without any organizational barriers that would impede them [8].

Competitive aggressiveness reflects the efforts of companies to outperform their rivals, and is strongly oriented toward defending market position and aggressive backlash to competitive action [8]. This characteristic can make a huge difference when new ventures struggle to compete with strong established companies.

\section{A. Entrepreneurial Orientation and Performance}

Although the relationship between the EO construct and firm performance has been widely investigated [11], [12], many questions remain unanswered. Relation between the entrepreneurial orientation and performance (as with any other variable) is extremely complex because it is moderated by many internal and external factors. Since service sector has only in the rarest of occasions has in the focus of EO research effort, we believe it is of utmost importance to test these relations and find out are there any factors which may play important role in service sector as opposed to other sectors, mainly production. We thus propose to test the following hypotheses and their corollaries:

H1: EO has a positive effect on small business performance.

H1a: Innovativeness has a positive effect on small business performance.

H1b: Proactiveness has a positive effect on small business performance.
H1c: Risk-taking has a positive effect on small business performance.

H1d: Autonomy has a positive effect on small business performance.

H1e: Competitive aggressiveness has a positive effect on small business performance.

Moreover, majority of previous studies did not bother to take into account both financial and non-financial performance indicators. Conceptual arguments concerning the EO-business performance relationship generally focus on financial profitability indicators, because firms characterized by higher level of EO may enter into premium market segments, may charge higher prices and may skim the market before their competitors do, which enables them to reap greater profits and engage in a faster expansion [17]. To find out more on the relationship between the EO and aforementioned variables, we propose to further test the following hypotheses:

H1.1: EO has a positive effect on small business financial performance.

H1.1a: Innovativeness has a positive effect on small business financial performance.

H1.1b: Proactiveness has a positive effect on small business financial performance.

H1.1c: Risk-taking has a positive effect on small business financial performance.

H1.1d: Autonomy has a positive effect on small business financial performance.

H1.1e: Competitive aggressiveness has a positive effect on small business financial performance.

Relationship between non-financial indicators and EO is not as direct as is the case of financial indicators. For this reason, we posit that the relationship between financial indicators and EO could be stronger than the one concerning non-financial indicators [11]. The present paper attempts to clarify this relationship. To that end, we propose to test the following hypotheses:

H1.2: EO has a positive effect on small business non-financial performance.

H1.2a: Innovativeness has a positive effect on small business non-financial performance.

H1.2b: Proactiveness has a positive effect on small business non-financial performance.

H1.2c: Risk-taking has a positive effect on small business non-financial performance.

H1.2d: Autonomy has a positive effect on small business non-financial performance.

H1.2e: Competitive aggressiveness has a positive effect on small business non-financial performance.

\section{B. External Environment and Entrepreneurial Orientation}

Many researchers suggest external environment not only has a strong influence on the EO, but also moderates the relationships between EO and other corollaries [18]. We take into account market turbulence - the rate of change in the 
composition of customers and their preferences [19], competitive rivalry - the degree of competitive intensity in the market and environmental dynamism - the rate of change in the environment [20]. In turbulent and dynamic environments where demands of supply and demand as well as applied technologies change quickly over time, new business opportunities will constantly be arising. This will provoke companies to be more innovative and make risky decisions in order not to lose pace and keep up with the competition. Likewise, it will provoke companies to be more proactive in order to foresee and grasp business opportunities, outperforming competitors in this way. To that end, we propose to test the following hypotheses:

\section{H2: The external environment has a positive effect on EO. \\ $\mathrm{H} 2 \mathrm{a}$ : Turbulence has a positive effect on EO. \\ $\mathrm{H} 2 \mathrm{~b}$ : Rivalry has a positive effect on EO. \\ $\mathrm{H} 2 \mathrm{c}$ : Dynamism has a positive effect on EO. \\ C. Interaction of Entrepreneurial Orientation, External Environment and Performance}

Previous research on the impact of entrepreneurial orientation on business performance of enterprises showed quite contradictory results. While research on the one hand showed a significant positive correlation between the observed indicators [11], on the other hand some studies have shown lack of significant correlation [21], [22] and even negative correlation [23]. It is evident, therefore, that there are moderating factors that direct effect of entrepreneurial orientation, which is in accordance with the requirements set by Lumpkin and Dess [8]. Since it is logical to assume that one of the most important moderating factors could be external environment, we hypothesize the following:

H3: The relationship between entrepreneurial orientation and small business performance is moderated by the external environment.

\section{RESEARCH METHOD}

\section{A. Sample}

The sampling frame was taken from the database of the Friuli-Venezia-Giulia Chambers of Commerce, which includes all incorporated companies in the region. Random sample of independent firms was taken where half of the sample had between 1 and 9 employees and half between 10 and 50 employees which correspond to the European Union definition of a micro and small enterprises. A total of 1.000 micro and small sized business owners/managers from the sampling frame were contacted in June and July of 2011 of which 85 responded to the mail questionnaire (response rate of $8.5 \%$ ). Regarding the business size of the respondents, $59 \%(n=50)$ were micro firms and $41 \%(n=35)$ small firms.

\section{B. Variables and Measures}

\section{1) Entrepreneurial orientation}

EO was operationalized using five variables: innovativeness, proactiveness, risk taking, autonomy and competitive aggressiveness. Each of these variables were measured with three questions using a seven point Likert scale. Innovativeness, proactiveness and risk taking were measured using Covin and Slevin's [24] scale, while autonomy was measured by Lumpkin, Cogliser and Schneider's [16] scale and competitive aggressiveness by the one provided by Aktan and Bulut [25].

\section{2) Business performance}

Analyzing SMEs business performance is extremely difficult since owners and their management are reluctant to reveal their business results. Therefore, this research was based on acquiring the subjective answers about the financial and non-financial performance from the entrepreneurs in order to reflect its multi-dimensionality. This approach has a foothold in the numerous studies of business performance where it has been shown that management subjective assessment of performance is highly correlated with objective performance measures [26], [27]. Therefore, business performance was conceptualized by Gupta and Govindarajan [28] where the respondents were asked to rate the extent to which stated financial and non-financial indicators are important for their business, and afterwards to assess the extent of satisfaction with the achieved performance of these indicators. For this purpose three financial and three non-financial indicators were used, measured with a seven point Likert scale.

\section{3) External environment}

External environment was conceptualized using three variables (turbulence, hostility and dynamism) by Naman and Slevin [29]. These variables were measured with three questions using a seven point Likert scale.

\section{Analysis}

Multiple linear regression analysis was used to test the relationships between strategic networking, external environment and business performance, while hierarchical linear regression analysis was used to test whether interaction effect of external environment on strategic networking and business performance relationship exists. Interaction effect represents the combined effects of independent variables on the dependent measure. More accurately, interaction effect is present when the impact of one variable depends on the level of the other variable and if the interaction term gives a significant contribution over and above the direct effects of the independent variables [30]-[32].

\section{REsUlTS}

The means, standard deviations and correlations of the variables are displayed in Table I, where it can be seen that correlations among the independent variables are relatively modest, ranging from -0.139 to 0.441 . The absence of multicollinearity was ensured by centering the means of the interaction variables and by applying multicollinearity diagnosis. Variance inflation factors were well below critical values.

Table II displays the means, standard deviations and correlations between the second-order variables, where it can also be seen that correlations among the second-order 
independent variables are relatively modest, ranging from -0.110 to 0.473 . Table III gives the results of hypotheses testing where each column presents the result of different hypothesis test. Columns 1,2 and 3 give the answer to the first hypothesis, column 4 to the second hypothesis, while column 5 gives the answer to the third hypothesis.

TABLE I: MEANS, S.D.S, AND CORRELATIONS $(N=85)$

\begin{tabular}{|c|c|c|c|c|c|c|c|c|}
\hline & Mean & S.D. & 1 & 2 & 3 & 4 & 5 & 6 \\
\hline 1. Performance & 23.24 & 8.31 & 1.00 & & & & & \\
\hline 2. Financial performance & 23.38 & 9.77 & $0.938 * *$ & 1.00 & & & & \\
\hline 3. Non-financial performance & 23.10 & 8.19 & $0.910 * *$ & $0.709 * *$ & 1.00 & & & \\
\hline $\begin{array}{l}\text { 4. Entrepreneurial orientation } \\
\text { (EO) }\end{array}$ & 4.71 & 0.96 & $0.364 * *$ & $0.214 * *$ & $0.482 * *$ & 1.00 & & \\
\hline 5. External environment (EE) & 5.03 & 0.94 & -0.030 & -0.031 & -0.023 & $0.184+$ & 1.00 & \\
\hline 6. $\mathrm{EOxEE}$ & & & -0.044 & -0.015 & -0.070 & -0.067 & 0.081 & 1.00 \\
\hline
\end{tabular}

Notes: +. Correlation is significant at the 0.1 level (2-tailed); *. Correlation is significant at the 0.05 level (2-tailed);

**. Correlation is significant at the 0.01 level (2-tailed).

TABLE II: MEANS, S.D.S, AND CORRELATIONS $(N=85)$

\begin{tabular}{|c|c|c|c|c|c|c|c|c|c|c|}
\hline & Mean & S.D. & 1 & 2 & 3 & 4 & 5 & 6 & 7 & 8 \\
\hline 1. Performance & 23.24 & 8.31 & 1.00 & & & & & & & \\
\hline 2. Financial perf. & 23.38 & 9.77 & $0.938 * *$ & 1.00 & & & & & & \\
\hline 3. Non-financial perf. & 23.10 & 8.19 & $0.910 * *$ & $0.709 * *$ & 1.00 & & & & & \\
\hline 4. Innovativeness & 4.94 & 1.19 & $0.330 * *$ & $0.206+$ & $0.424 * *$ & 1.00 & & & & \\
\hline 5. Proactiveness & 4.78 & 1.39 & $0.340 * *$ & $0.181+$ & $0.473 * *$ & $0.489 * *$ & 1.00 & & & \\
\hline 7. Autonomy & 4.85 & 1.19 & 0.153 & 0.077 & $0.219 *$ & $0.395 * *$ & $0.202+$ & $0.522 * *$ & 1.00 & \\
\hline 8. Comp. aggress. & 4.20 & 1.37 & $0.245^{*}$ & $0.192+$ & $0.269 *$ & $0.486 * *$ & $0.404 * *$ & $0.458 * *$ & $0.453 * *$ & 1.00 \\
\hline 9. Turbulence & 5.13 & 1.29 & -0.104 & -0.083 & -0.113 & -0.110 & 0.036 & 0.075 & -0.036 & -0.104 \\
\hline 10. Hostility & 5.12 & 1.06 & -0.089 & -0.068 & -0.100 & -0.067 & -0.007 & 0.077 & 0.099 & $0.284 * *$ \\
\hline 11. Dynamism & 4.83 & 1.30 & 0.112 & 0.070 & 0.143 & $0.261 *$ & $0.209+$ & $0.265^{*}$ & $0.186+$ & $0.340 * *$ \\
\hline
\end{tabular}

Notes: +. Correlation is significant at the 0.1 level (2-tailed); *. Correlation is significant at the 0.05 level (2-tailed);

**. Correlation is significant at the 0.01 level (2-tailed).

TABLE III: RESULTS OF MULTIPLE LINEAR REGRESSION ANALYSIS ( $N=85$ )

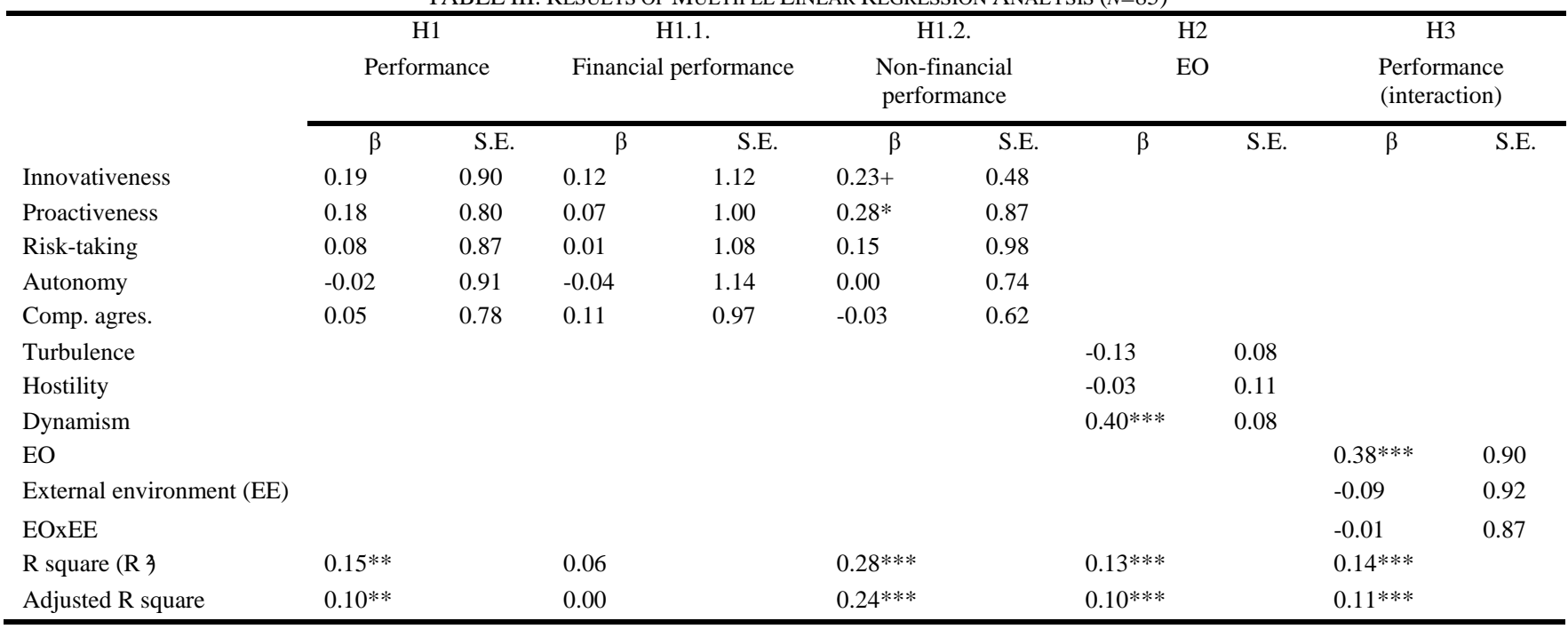

Notes: $* P<0.10 ; * * P<0.05 ; * * * P<0.01$.

Entrepreneurial orientation, as a first order variable, has a significantly positive effect on the business performance $(r=$ $0.364, P<0.01)$, financial business performance $(r=0.214$, $P<0.01)$ and non-financial business performance $(r=0.482$, $P<0.01)$ which provides support for Hypothesis $1,1.1$ and 1.2. From the second order variables that conceptualize entrepreneurial orientation only innovativeness $(b=0.23, P<$ $0.10)$ and proactiveness $(b=0.28, P<0.05)$ have significantly positive effect on non-financial performance, while there have not been found any significantly positive influence on the financial and overall business performance. Therefore, the findings support only the Hypothesis $1.2 \mathrm{a}$ and $1.2 \mathrm{~b}$.

External environment has a positive influence on the entrepreneurial orientation ( $r=0.184, P<0.10)$, supporting the Hypothesis 2, while only dynamism as a second order variable that conceptualize external environment has a significantly positive effect on the entrepreneurial orientation 
( $b=0.40, P<0.01$ ), which supports the Hypothesis 2.c. Regarding the moderation effect of external environment on the relationship between strategic networking and business performance it can be concluded that as such it does not exists, therefore there is not enough evidence to support the Hypothesis 3.

\section{CONCLUSION AND IMPLICATIONS FOR FURTHER RESEARCH}

In the existing literature, entrepreneurial orientation can be captured by the propensity to act autonomously, the tendency to be aggressive toward competition, to proactively pursue market opportunities, and to have the willingness to innovate and bear risk [14]. This research explored the concept of entrepreneurial orientation by measuring corresponding variables: innovativeness, proactiveness, risk taking, autonomy and competitive aggressiveness. As assumed by first hypothesis, empirical findings confirmed the positive relationship between entrepreneurial orientation and financial and non-financial performance of companies. It is thus clear SMEs should nurture corporate culture and management styles aimed at promotion of innovative, proactive and risk taking behavior.

Research has also confirmed positive relation between external environment and entrepreneurial orientation as assumed by second hypothesis. Greater and faster changes in the marketplace (as indicated by market dynamism and market turbulence) open new market opportunities. When those factors are accompanied with intense competition (as indicated by market rivalry), entrepreneurial orientation represents a sine qua non company subsistence and positive performance.

Size of the sample represents a certain limitation of the study. Although the sample size and the rate of return are satisfactory and in line with the international publication standards [33], [34], conducting future research on a larger sample would significantly contribute to the understanding of the research issues. Since the research was conducted at one point in time, future research work should be continued over a longer time period with the aim that longitudinal research would provide a more clearer insights into the relationship of entrepreneurial orientation and various aspects of business performance. Moreover, study is based on subjective perceptions of firm representatives, comprised of the owners, directors or higher-level management, where directors and managers are personally biased whilst evaluating internal and external organizational environment and performance.

Limitations can be found in the research design as well. From a methodological point of view, research design could be improved if the study includes several representatives from each investigated company and not solely rely on the answers provided by only one representative of each firm. Since the research is based solely on subjective measures of observed concepts, i.e. on the individual perceptions of individual firms' representatives, it is necessary to develop certain objective measures so they could be compared with subjective measures which would in turn provide a better understanding of the observed relationships and an increase in the overall reliability of the analysis.
Most of our findings have been in line with the existing research on entrepreneurial orientation. Contrary to our prediction, although in line with the existing literature, we found no evidence for moderating performance of external environment on the relationship between entrepreneurial orientation and small business performance. In any case, this necessitates for additional research and taking into account different variables that might interact with and alter the relationship(s) between the observed variables.

\section{REFERENCES}

[1] A. M. Moreno and J. C. Casillas, "Entrepreneurial orientation and growth of SMEs: A causal model," Entrepreneurship Theory and Practice, vol. 32, issue 3, pp. 507-528, 2008.

[2] A. Bonaccorsi, "What do we know about exporting by small Italian manufacturing firms?" Journal of International Marketing, vol. 1, pp. 49-75, 1992.

[3] J. A. Welsh and J. F. White, "A small business is not a little big business," Harvard Business Review, vol. 59, no. 4, pp. 18-32, 1980.

[4] F. H. Knight, "Risk, uncertainty, and profit," Hart, Schaffner and Marx Prize Essays, no. 31, Boston and New York: Houghton Mifflin, 1921.

[5] J. A. Schumpeter, The Theory of Economic Development, Cambridge: Harvard University Press, 1934.

[6] T. Bird and M. Jelinek, "The operation of entrepreneurial intentions," Entrepreneurship Theory and Practice, vol. 13, issue 2, pp. 21-30, 1988.

[7] H. T. Keh, T. T. M. Nguyen, and P. N. Hwei, "The effects of entrepreneurial orientation and marketing information on the Performance of SMEs," Journal of Business Venturing, vol. 22, pp. 592-611, 2007.

[8] G. T. Lumpkin and G. G. Dess, "Clarifying the entrepreneurial orientation construct and linking it to performance," Academy of Management Review, vol. 21, pp. 135-172, 1996.

[9] N. Venkatraman, "Strategic orientation of business enterprises: The construct, dimensionality, and measurement," Management Science, vol. 35, pp. 942-962, 1989.

[10] P. M. Kreiser, L. D. Marino, M. K. Weaver et al., "Reassessing the environment-eo link: The impact of environmental hostility on the dimensions of entrepreneurial orientation," Academy of Management Proceedings \& Membership Directory, pp. G1-G6, 2002.

[11] J. Wiklund and I. D. Shepherd, "Entrepreneurial orientation and small business performance: A configurational approach," Journal of Business Venturing, vol. 20, pp. 82-83, 2005.

[12] G. T. Lumpkin and G. G. Dess, "Linking two dimensions of entrepreneurial orientation to firm performance: The moderating role of environment and industry life cycle," Journal of Business Venturing, vol. 16, pp. 429-451, 2001

[13] K. Atuahene-Gima and A. Ko, "An Empirical investigation of the effect of market orientation and entrepreneurial orientation alignment on product innovation," Organization Science, vol. 12, pp. 54-74, 2001.

[14] J. G. Covin and D. P. Slevin, "A conceptual model of entrepreneurship as firm behavior," Entrepreneurship Theory and Practice, vol. 16, pp. 7-25, 1991.

[15] S. Baird and H. Thomas, "Toward a contingency model of strategic risk taking," Academy of Management Review, vol. 10, issue 2, pp. 230-243, 1985.

[16] G. T. Lumpkin, C. C. Cogliser, and D. R. Schneider, "Understanding and measuring autonomy: An entrepreneurial orientation perspective," Entrepreneurship Theory and Practice, vol. 33, issue 1, pp. 47-69, 2009.

[17] S. A. Zahra and J. Covin, "Contextual influence on the corporate entrepreneurship-performance relationship: A longitudinal analysis," Journal of Business Venturing, vol. 10, pp. 43-58, 1995.

[18] S. A. Zahra and D. M. Garvis, "International corporate entrepreneurship and firm performance: The moderating effect of internal environmental hostility," Journal of Business Venturing, vol. 15 , issue 5/6, p. 469, 2000.

[19] K. Kohli and B. J. Jaworski, "Market orientation: antecedents and consequences," Journal of Marketing, vol. 57, pp. 53-70, 1993.

[20] W. Mohd, S. Idris, and R. A. Momani, "Impact of environmental dynamism on marketing strategy, comprehensiveness and organizational performance," International Journal of Business and Management, vol. 8, issue 9, pp. 40-49, 2013. 
[21] H. Li, Y. Zhang, and T. S. Chan, "Entrepreneurial strategy making and performance in China's new technology ventures: The contingency effect of environments and firm competences," Journal of High Technology Management Research, vol. 16, issue 1, pp. 37-57, 2005.

[22] W. Stam and T. Elfring, "Entrepreneurial orientation and new venture performance: the moderating role of intra- and extra-industry social capital," Academy of Management Journal, vol. 51, pp. 97-111, 2008.

[23] S. L. Hart, "An integrative framework for strategy-making processes," Academy of Management Review, vol. 17, pp. 327-351, 1992.

[24] J. G. Covin and D. P. Slevin, "Strategic management of small firms in hostile and benign environments," Strategic Management Journal, vol. 10, pp. 75-87, 1989.

[25] B. Aktan and C. Bulut, "Financial performance impacts of Corporate entrepreneurship in emerging markets: A case of Turkey," European Journal of Economics, Finance and Administrative Sciences, issue 12, pp. 69-79, 2008.

[26] G. G. Dess and R. B. Robinson, "Measuring organisational performance in the absence of objective measures: the case of the privately-held firm and conglomerate business unit," Strategic Management Journal, vol. 5, issue 3, pp. 265-273, 1984.

[27] N. Venkatraman and V. Ramanujam, "Measurement of business performance in strategy research: A comparison of approaches," Academy of Management Review, vol. 11, pp. 801-814, 1986.

[28] A. K. Gupta and V. Govindarajan, "Business unit strategy, managerial characteristics, and business unit effectiveness at strategy implementation," Academy of Management Journal, vol. 27, pp. 25-41, 1984.

[29] J. J. Naman and D. P. Slevin, "Entrepreneurship and the concept of fit: A model and empirical tests," Strategic Management Journal, vol. 14, pp. 137-153, 1993.

[30] J. Cohen and P. Cohen, Applied Multiple Regression/Correlation Analysis for the Behavioral Sciences, 2nd ed. Lawrence Erlbaum Associates, Hillsdale, New Jersey, 1983.

[31] E. J. Pedhazur, Multiple Regression in Behavioral Research, 3rd ed. Fort Worth, Harcourt Brace, Texas, 1997.
[32] E. J. Pedhazur and L. P. Schmelkin, Measurement, Design, and Analysis: An Integrated Approach, Hillsdale, Erlbaum, New Jersey, 1993.

[33] R. B. Kline, Principles and Practice of Structural Equation Modeling, 2nd ed. The Guilford Press, New York, 2005.

[34] N. M. Malhotra, Marketing Research: An Applied Orientation, Pearson, New Jersey, 2010.

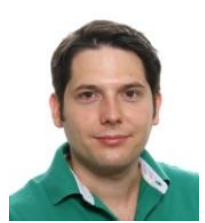

Bojan Morić Milovanović is a senior research assistan at the Department of Managerial Economics at the Faculty of Economics and Business, University of Zagreb. He received his MA and Ph.D. at the same University. During and after his studies, he completed programs of some prestigious international universities such as the London School of Economics and Political Science, University of Hong Kong, Wirtschafts University of Vienna and others. His areas of interest include entrepreneurship, finance and design business.

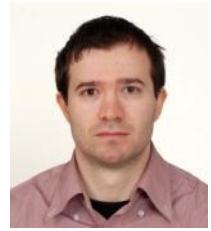

Zoran Wittine is a senior research assistant at the Department of International Economics at the Faculty of Economics and Business, University of Zagreb. He received his M.Sc. and Ph.D. at the same University. During and after his studies, he completed programs of some prestigious international universities such as the London School of Economics and Political Science, Georgetown University, Wirtschafts University of Vienna and others. Since 2005 he had worked for McKinsey \& Company for a year, after which he moved to his current employer. His areas of interest include international business and risk management. 